\title{
Mind the Gap: Beyond Whole-brain learning
}

Marth Munro \& Marié-Heleen Coetzee

Tshwane University of Technology \& University of Pretoria

In past research we ${ }^{1}$ have demonstrated how methodologies used in the training of performers can both encourage whole-brain learning and answer to the demands of South Africa's current educational paradigm, outcomes-based education (OBE). OBE is a needs-driven, outcomes-driven and competency-orientated pedagogy, which aims at incorporating learners as active agents within the learning process as opposed to the previous content-driven, teacher-orientated approach to education (Coetzee 2004).

Our research was prompted by the constant need for our Drama departments to validate their existence in the light of changing funding structures for the arts, governmental and institutional demands for measured outcomes and our institutions' emphasis on wholebrain learning as the preferred pedagogical approach to education and training. We explored the ways in which the changes in the South African educational dispensation impact on the work of educators within a Drama department in the Higher Education and Training band (HET) in South Africa. These changes include a focus on competencies and critical outcomes across learning areas and across the qualification bands identified by the new National Qualifications Framework. In our search for ways in which to

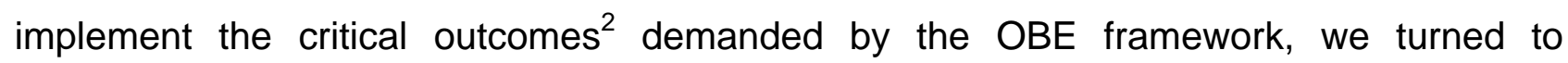
Herrmann's argument (1995) that optimal, deep structure learning can only take place when whole-brain modes are operative. Our investigations were supported by research undertaken by De Boer, Steyn and Du Toit (2001:192) in which they indicated compatibility between the processes associated with each of the four modalities that constitute whole-brain learning and the processes associated with reaching OBE's critical outcomes as demonstrated in Table 1 on the next page.

Our research made specific reference to the Lessac system (Munro and Coetzee, 2005), Laban Movement Studies (Coetzee, Munro and De Boer 2005) and Drama-in-Education (Coetzee and Munro 2007). 
Table 1: Processes and quadrants

\begin{tabular}{|l|l|}
\hline $\begin{array}{l}\text { Process necessary to } \\
\text { achieve OBE outcomes }\end{array}$ & $\begin{array}{l}\text { Associated quadrants in the } \\
\text { Herrmann model }\end{array}$ \\
\hline Critical thinking & $\mathrm{A}, \mathrm{B}, \mathrm{C}$, \& D \\
\hline Problem solving & $\mathrm{A}, \mathrm{B}, \mathrm{C}$, \& D \\
\hline Application & $\mathrm{B}$ \\
\hline Appreciation & $\mathrm{A}, \mathrm{B}, \mathrm{C}, \& \mathrm{D}$ \\
\hline Analysing & $\mathrm{A}$ \\
\hline Synthesising & $\mathrm{D}$ \\
\hline Evaluation of information & $\mathrm{A}, \mathrm{B}, \mathrm{C}$, \& D \\
\hline Teamwork & $\mathrm{C}$ \\
\hline Communication & $\mathrm{A}, \mathrm{B}, \mathrm{C}, \& \mathrm{D}$ \\
\hline Socialising & $\mathrm{C}$ \\
\hline
\end{tabular}

(De Boer, Steyn and Du Toit 2001: 192)

Whilst interrogating the Lessac Approach, we investigated voice pedagogies in the context of OBE and whole-brain learning. We found that, in the field of voice for theatre, many well-known approaches to voice training are primarily embedded in two of Herrmann's whole-brain modalities, with little emphasis on the analytical or critical thinking frameworks that both the metaphorical whole-brain model and OBE emphasise. The Lessac Approach is a widely used theatre voice system that addresses projection, pronunciation and prosodic elements through organic body/voice usage. We concluded that the Lessac Approach facilitates the engagement of all four whole-brain modalities as it guides the educator to focus on the epistemological approach to the pedagogy, the physiological effect of the pedagogy and the acoustical outcome of the pedagogy.

In a separate study we explored how Laban/Bartenieff Movement Studies ${ }^{\text {TM }}$ (LMS) operates as a strategy for teaching and learning that accommodates the fundamental initiatives of OBE, whilst supporting the institutional drive towards whole-brain learning. LMS is a movement-specific vocabulary used as a descriptive framework for observing, analysing and practising movement (Madden \& Gantz 1989:117). We located this research in body/voice integration training for drama students on HET level and explored the practical implications of this research with reference to the production Sitelines. The production was designed to facilitate a learning opportunity where learners could focus on the application of body/voice integration in a performance situation, directly apply the knowledge and skills they discovered in the body/voice integration curriculum to a 
performance context, engage with OBE learning structures, and foster whole-brain learning. We used LMS as the central methodology in teaching, performing and directing/choreographing the production. We demonstrated how the methodology allowed for multi-mode learning opportunities and fostered deep-structure learning and how LMS as a teaching methodology allows for whole-brain processes to be related to the OBE critical outcomes.

In the paper (Coetzee \& Munro 2007) engaging with drama-in-education (DIE), DIE was interpreted as the use of drama as a teaching methodology. In this exploration of drama methodologies in the context of OBE and the Herrmann metaphorical model, we argued that drama-in-education supports the ideas of both OBE and whole-brain learning on the HET level by creating the critical interface between the OBE critical outcomes and processes, and the Herrmann whole-brain modalities. We based our postulation on the convergences between the philosophical underpinnings, critical outcomes and processes of OBE and those of DIE as well as on our observation that the processes associated with the use of DIE are comparable to processes associated with all four of the metaphorical quadrants of the Herrmann model of whole-brain learning. We demonstrated how three key elements of DIE (dramatic play, role play and empathy) facilitate the interface between OBE and the Herrmann whole-brain model. We highlighted the ways in which the interplay between these three elements opens up a third space of learning that integrates the quadrants, engages the processes necessary to achieve the critical outcomes associated with OBE, addresses these outcomes, and encourages optimal and transformative learning.

In our explorations we realised that a central concept of all these methodologies used in theatre performance training at an HET level is covertly embedded in OBE, but it is only very tangentially addressed in the Herrmann metaphorical model. This central concept is that the bodymind/brain processes, integrated with an emotional state, comprise an interconnected whole/unit/entirety that stands central to training and education in general (Caine, Caine, McClintic \& Klimek 2005:xii) and is specific to all performer training.

The question that thus arises from this observation is whether, during moments of learning, the metaphorical whole-brain model does indeed optimally explain deep structure learning as Herrmann posits. It is our contention that it does not, because it does not integrate bodymind processes and emotional states. It does not seem as if Herrmann explicitly positions the body as an agent of knowing and learning within this metaphorical 
four-quadrant model. Herrmann's postulations focus primarily on a mind/brain interaction, although he acknowledges a kinaesthetic style of learning. This acknowledgement of the kinaesthetic style does not locate the bodymind as a centrifugal force of the learning experience.

In order to substantiate our claims, this paper frames and traces the whole-brain learning approach, specifically drawing from Ned Herrmann's (1995) metaphorical model. Secondly, it explores the notion of bodymind by defining the concepts of body, brain and mind. It further articulates the influence of emotions during the learning process. Finally, it proposes a revised model of whole-brain learning, merging the existing model with bodymind and emotion as frames and filters in learning moments.

\section{The whole-brain learning approach}

Herrmann (1995) posits that optimal and deep structure learning can only take place when the whole brain is involved. Optimal learning experiences are facilitated by the engagement of the brain in its entirety in a learning situation.

Herrmann's four-quadrant metaphorical model is an organising principle based upon scientific evidence relating cognition to physiological processes (see Herrmann 2001). Herrmann (2000) views the brain as consisting of two cerebral halves (right/left hemispheres) and two limbic halves (right/left parts of the limbic system), which are inextricably interwoven. In doing so, he draws upon Sperry's notion that the brain is physically divided into a left and a right hemisphere, and that there are physical and neurological connections between the two hemispheres. He further draws on McLean's theory of the triune brain. McLean posits that the brain is split into three "brains" that overlay each other. The more "primitive" brain relates to instinct, the mid-brain to emotion and the most "evolved" brain to cognitive processes. These "brains" share a physical inter-connectedness between the upper (more "evolved") and lower (more "primitive") parts of the brain (Herrmann 1995; De Boer, Steyn \& Du Toit 2001). Herrmann (1995) notes that, during the collection of the data regarding his four-quadrant model, it was evident that the data were consistent, but that they were richer than simply left-right data or a triune interpretation of the brain.

It is currently accepted that the brain functions are incredibly subtle and complex and cannot, as believed before, be clearly attributed to various sides or places in the brain. For Herrmann, the cerebral and limbic pairs collectively represent the brain as a whole that is 
divided into four quadrants. Despite the scientific basis of the whole-brain model, Herrmann (2001) underlines that it is a "descriptive metaphor" that illustrates four different modes of thinking, or thinking structures, rather than a model locating specific "physiological substrates" (Herrmann 2001).

\section{Figure 1: Herrmann's metaphorical four-quadrant model}

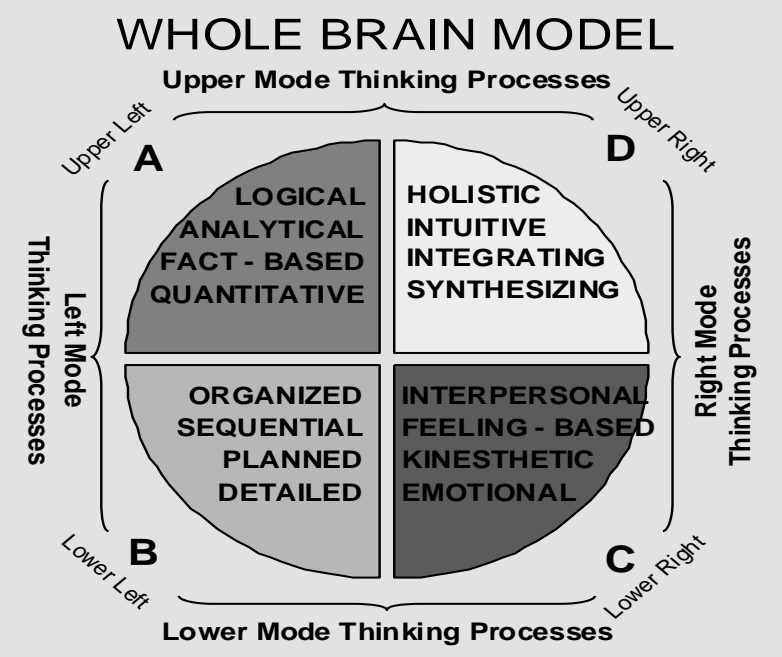

(Herrmann 1995:155)

It is generally acknowledged that whole-brain thinking is typified by the situational use of all four quadrants of the brain, as required in various contexts. These modes of thinking influence learning preferences and learning styles (Herrmann 1995; De Boer, Steyn and Du Toit 2001). As the brain is an "evolving coalition of many preferences", an individual's preferences develop in accordance with life experiences and the "degree of dominance that has developed among the four thinking structures of the brain" (Herrmann 2000).

Learning preferences imply that persons have degrees of preference for thinking as well as different learning styles. These differences can be clustered according to thinking and learning dynamics or processes that are specific to each of the four metaphorical quadrants. An awareness of one's own thinking style, the thinking styles of other people and the ability to perform outside of one's own learning style can assist one to improve skills and processes associated with less preferred quadrants (Braindominance online).

The metaphorical four-quadrant whole brain model specifically indicates that learning preferences suggest that learners favour one or more quadrant(s) of the metaphorical model, and that learning preferences and styles are not synonymous to learning abilities (Coetzee, Munro and De Boer 2004: 140-141). A person may be able to function in all the four metaphorical quadrants, but may prefer only one or more of these quadrants. 
However, Herrmann (1995) emphasises that deep structure learning takes place predominantly when all four quadrants are engaged.

Herrmann (2001) further views the organising principle of the whole-brain model to contain four distinct "selves", typified by what he calls the "descriptive concepts" of the rational self (A quadrant), the safekeeping self ( $B$ quadrant), the feeling self ( $C$ quadrant) and the experimental self (D quadrant). These "selves" relate to modes of knowing and learning that stand central to performer training. In the moment of learning, certain phrases and colloquial terms may be used to identify or typify aspects of each of the metaphorical quadrants and may indicate the learning preference of the self. Examples of these phrases and terms are provided in Table 2 below.

Table 2: Phrases and terms describing learning preferences

\begin{tabular}{|l|l|l|l|}
\hline Upper Left (A) & Lower left (B) & Lower Right (C) & Upper Right (D) \\
\hline Logical Leap & $\begin{array}{l}\text { Getting from A to } \\
\text { B }\end{array}$ & Reaching out & $\begin{array}{l}\text { A road to the } \\
\text { future }\end{array}$ \\
\hline $\begin{array}{l}\text { Achieving it } \\
\text { together }\end{array}$ & Putting it together & Doing it together & Getting it together \\
\hline Ability & Efficiency & Harmony & Synergy \\
\hline Amount & Protect & Acknowledge & Use \\
\hline Know it & Do it & Sense it & Try it \\
\hline Fact & Form & Feeling & Fantasy \\
\hline
\end{tabular}

(Herrmann 1995:421-422)

Herrmann's emphasis on the complex interrelated functioning of the brain and the limbic system (see below) relies upon the use of teaching methodologies that (1) promote a whole-brain approach to teaching and learning, (2) provide for diversity of learning preferences, and (3) stimulate the use of all four quadrants.

Referring to Figure 1, it is evident that Herrmann places both the body (as part of a kinesthetic style) as well as emotion, within the lower right quadrant of the metaphorical model. The kinaesthetic style of learning and emotion are located as potential, perhaps even discrete, learning preferences and styles only within this quadrant and not as all encapsulating centrifugal forces of the learning process. Herrmann, thus, does not explicitly position the body as an agent of knowing and learning within the metaphorical four-quadrant model. However, the integration or synthesising preferences occur in the upper right quadrant, and inevitably this would mean that one would need the one to do 
the other. Put another way, the question arises whether the presence of the body and emotion in the lower right quadrant and the preference of integration and synthesis in the upper right quadrant will necessarily create a discourse between all four quadrants. What if these quadrants are not the preferred modes of learning and knowing for the learner? What if the preferences and learning styles are stationed in the other two quadrants? It seems that Herrmann's postulations focus primarily on a mind/brain and do not acknowledge "bodymind" and emotion as primary filters for, and agents of, optimal learning, irrespective of quadrant preference.

In the training of performers whole-brain learning takes place within the bodymind activity, which includes emotion ${ }^{3}$ (Kozik-Rosabal 2001:104). This is substantiated by observations made, and the outcomes of, our three projects mentioned earlier. From this, we hypothesize that bodymind activity may potentially allow for optimal functioning of all four metaphorical quadrants whilst creating a free-flow and interconnectivity between the modes of knowing and the learning processes associated with the four quadrants. Perhaps more speculatively, we suggest that bodymind, and the integrated emotional state, foster a smoother and more open transition from learning preference dominant quadrants to less usually accessed quadrants by the learner. This stimulates meta-learning (deep structure learning) and meta-cognition on an epistemological level. As such, we argue that the methodologies used in the training of performers move beyond Herrmann's whole-brain practices. In order to interrogate this hypothesis one has to unpack the concept of bodymind.

Any understanding of how one learns, understands and interacts with the world has to acknowledge an ontological position that is the core of the explanation on learning, understanding and interacting. In the bodymind process the ontological position is embedded in the debate as to whether the world is understood from a dualist or monist ontology. A dualist ontology (as suggested by Descartes, ${ }^{4}$ for example) posits the view that there is a separation between ways of knowing, and things known, or between cognitive engagement, on the one hand, and a body being in the world, on the other. A monist ontology ${ }^{5}$ operates from the position that knowing and being are inseparable, or that there is a wholeness or inclusiveness to any act of meaning generation. Inevitably the ontological position one takes works its way through to the epistemological platform (that is to say, systems of knowledge), like education, psychology or aesthetics, for example, and from there into particular areas of concern, like drama or theatre, for example. On a teleological level this may reflect in (for example) the use of the Brechtian style of acting 
versus the Method style of acting. This paper concerns itself with the pedagogical implications of performer training and thus the ontological position is stated to frame the epistemological and teleological aspects of the argument. The epistemological counterpoint of this paper is the notion of the bodymind as a mode of knowing and learning.

In this search to understand the role of bodymind in the pedagogical process of the training of performers, the concept of bodymind has to be defined. The term bodymind simultaneously conjures up the seemingly opposing notions of scientific analysis and esoteric musings. The semantic instability, from which the constituencies of the term bodymind suffer, further clouds understanding. In order to clarify the interpretation of bodymind for the purposes of this article, the concepts that construct bodymind have to be addressed. These concepts are by implication body, brain and mind.

\section{Body}

The body is at the centre of many approaches to actor training (Meyerhold, Grotowski, Suzuki, Staniewski, Alba Emoting and Viewpoints - see Zarrilli 2002; Watson 2001; Tabish 1995; Bogart 2005; Richards 1995) and to somatic disciplines that are often applied to actor training (Alexander, Feldenkrais, Ideokinetics, Chladek, Laban, Lessac, Fitzmaurice and others).

The body is generally seen as the physical, corporeal structure through which lived experiences and actions are embodied, organised by neural activity. Common-sense assumptions about 'body' position the body as a stable locality, an "organic, undifferentiated presence" (Auslander in Zarrilli 2002: 58) or what Zarrilli terms "an essential 'real'" (2002:15), supported by the immediacy and tangibility of the body. This perspective confers an object-status on the body that supports a dualistic interpretation of 'being'.

Csordas (1994:1-6) points out, however, that the prolific literature that has emerged in recent years around notions of 'the body' does not allow for the body to be considered a fixed, material, biological factor existing prior to cultural change any longer. The wealth of theoretical approaches to 'the body' approaches the body as a performative, as a politic, as interrelated with domains of socio-cultural activity, amongst other things. Furthermore, the materiality and corporeality of the body in itself is brought into question by, for example, the dissolving boundaries between the organic and the inorganic. Drawing on 
Frank, he suggests that the body has to be understood as an epitome of the flux of cultural and historical change, not as a constant amidst this flux (Csordas 1994:2). The body both constitutes/represents the cultural and historical change, and it is constituted/represented by the same change.

Scholars such as Merleau-Ponty (in Fraser and Greco 2005), Auslander and Zarrilli (in Zarrilli 2002) echo this point of view by positioning the body as simultaneously a physical and a conceptual construct and the outcome of discursive practices. Merleau-Ponty further asserts the primacy of the lived experience in the construction of meaning, reclaiming the centrality of the body and embodied experience as locus for knowing and knowledge creation. Merleau-Ponty goes as far as to position the body as a "function of being-in-the-world" (Csordas 1994:12). Because he viewed the body as the entity through which humans gain access to the world, he viewed the world as perceived through the body as the base line for gaining and creating knowledge. The body is captured in time, space, history and culture and captures time, space, history and culture. As such, body constantly involves the "experience of social being" (Lyon and Barbalet 1994:60). The body thus assumes a subject status (of experience, sensation and world), rather than only an object status. The body-as-subject locates embodiment as "existential ground of culture and self" (Csordas 1994:6-8), an "indeterminate methodological field defined by perceptual experience and mode of presence and engagement in the world" (Csordas 1994:12). Embodiment seamlessly integrates thinking, being, doing and interacting and acts as a sight as well as a site of reflection.

It is the interface between the physical body (or what Merleau-Ponty refers to as the "objective body" - Fraser and Greco 2005:52), the phenomenal body and the discursively created body that creates our concept of 'body' as used in this article. To us, this implies and foreshadows the notion of bodymind.

In order to define the concept of mind, one has to investigate the biological concept of brain. Mind and brain can be discussed separately only for the purposes of analysis or explanation, as they are inseparable as an entity. Andreasson (1997:1586-1593), for example, explains that phenomena related to mind arise from brain, but activities of mind affect brain as well. 


\section{Brain}

In accordance with prior research, we view brain as the physical, anatomical, mechanical functioning of an organism and the site of mental activities (Thurman \& Welch 1997; Jensen 1998) situated within and, interacting with, the physical body. The brain is never in direct contact with the environment as a reality, as information from the environment must be electrically and chemically coded/mediated to enter the nervous system (Jensen 1998:30). The brain deals with the symbolic representation of material realities. The brain creates neural codes via sensory receptors that are necessary for processing, evaluating, storing and recovering information, and triggering behavioural patterns. The development of the brain is dependent on genetics, maturation over time, individual experience and interaction with the world. According to Thurman \& Welch (1997), the brain is the locus for regulating bodily processes, for the perception and interpretation of sensory experiences, the internal stimulus for movement, thought, conscious and extra-conscious awareness, moods and emotions. The brain creates the interface between the immune system and the endocrine system that carries out, amongst other functions, learning (Thurman \& Welch 1997:3, Hannaford 1995:168). The limbic system (also known as the mid-brain) regulates involuntary and endocrine functions, specifically in relation to emotional stimuli. It sets levels of arousal, is connected to motivation and reinforcing behaviours, and is crucial to certain types of memory (Review of clinical and functional neuroscience online). The limbic brain's connection to learning and emotion will be considered below.

\section{Mind}

When interpretation is isolated (for the sake of the argument) from the processes that are taking place in the physical organism of the brain, the brain becomes mind. It is "the Cartesian subject of rational thought and moral reflection" (Csordas 1994:8). In current literature, mind is generally described as an active process (Jensen 1998), rather than a stable entity. Mind encompasses brain. Mind develops over time as individuals learn how to learn, and is influenced by various factors such as culture, environment and activities (Thurman \& Welch 1997:11). Mind is dependent on the existence of brain and therefore also body. It represents an inner faculty and its primary function is to resonate with or simply resonate the external world. ${ }^{6}$ Experiences associated with the mind and sensory responses to experiences (bodymind) change the anatomical and physiological structure of the brain (Thurman \& Welch 1997:15).

Following on from these definitions of the concepts of body, brain and mind, it is necessary to clarify the concept bodymind. Damasio states that "It is not only the 
separation between mind and brain that is mythical: the separation between mind and body is probably just as fictional. The mind is embodied, in the full sense of the term, not just embrained" (Damasio 1994: 118).

\section{Bodymind}

Scholars have attempted to explain and prove the existence of bodymind (another assumption underlying many of the approaches to performer-training) through various methods. $^{7}$

On a biological level, neuropeptides and their receptors are the keys to understanding bodymind (see Pert 1986). The bodymind activates movement, sensation, perception, mood, feeling/emotion, behaviour, thought and memory. It can modify or re-establish patterns of learning and knowing. Sensory inputs structure the mind, and the mind cannot exist without manifestations of inner perceptions embodied. Mind is so intimately shaped by body and body by mind that only one mind could possibly arise in one body. "Bodyminded minds help save the body" (Damasio 1999:143). "Whatever happens in your mind, happens in time and in space relative to the instant in time your body is in and to the region of space occupied by your body" (Damasio 1999:145).

Bodymind is a way of being, knowing and learning through which "our embodied awareness unfolds through engaging/embracing our experiencing." (Hocking, Haskel \& Linds 2001:xviii). Although one should be careful not to reduce bodymind to a scientific phenomenon, one should acknowledge the physiological inter-being of body and mind. Bodymind is a process of constant flow and is more than the sum of its parts. Bodymind learning and knowing can be cognitive or extra-cognitive, conscious or unconscious. According to Thurman \& Welch (1997:15), about $90 \%$ of the "bodymind's processing capacity is unconscious". In the learning process the educator needs to facilitate ways through which the unconscious can be made conscious and the extra-cognitive articulated. In the context of body/mind, a interactivity arises: learning through the bodymind and learning because of the bodymind. This holds true for emotion in the learning process as well. Learning through the bodymind positions the bodymind (and thus the body per se) as a knowing subject. As stated above, this approach is at the centre of various methodologies used in performer training, for example, Alba Emoting (Watson 2001:207), Grotowski (Wolford 2000:198-200) and Laban Movement Studies (Madden and Gantz 1989). In these approaches the role of the emotions as an 
agent in learning is implicitly acknowledged. This acknowledgement is supported by scholarship on the relationship between emotions and the limbic system. ${ }^{8}$

The limbic system's role in brain activity is increasingly acknowledged in optimal learning. We postulate that the limbic system, in addition to the systems discussed in relation to brain, is central to learning responses (see Hannaford 1995; Thurman \& Welch 1997; Caine et al. 2005; Jensen 1998). According to Lyon and Barbalet (1994:60), there is an interrelationship between affect, learning and memory. Norman (1999:11), echoing Lyons and Barbalet (1994), argues that emotion and feeling are critical to learning. Norman refers to the functions of the limbic brain to support his notion that learning and meaning making depend on the engagement of emotion. Feeling responses are linked to memory; as such learning has to be personalised and has to entail emotional arousal to be optimal. Carter (1999:164) argues for an "emotional excitement" to enhance memory due to the fact that this excitement "is brought about by a surge of excitatory neuro-transmitters that increase the firing rate of neurons in certain parts of the brain".

Following Lyon and Barbalet (1994:48), we view emotion as the 'excitation mechanism' between the social world and the body. Here the social world includes learning contexts. We thus view emotion as central to the integration of the thinking and knowing process linked to the metaphorical quadrants, and as such to learning. In essence then, we posit that emotion acts both as a filter in learning and an enhancing process within the moment of learning. Concluding from this, successful bodymind learning will have to be pre-empted by an optimal emotional state directed towards learning (Caine et al, 2005:18; Damasio 1999:41, 61-62).

Current thinking emphasises the importance of involving emotion in education (Diamond \& Mullen in Mirochnik \& Scherman 2002). Furthermore, Csordas's reading of Lyon and Barbalet (1994:14) proposes that the role of emotion in social life can further negate the body-as-object and objectification processes, as long as emotion is "construed as both embodied" and "social or relational in its origins and consequences". These notions are features of methodologies used in performer training (examples mentioned earlier). If one extends Csordas's notion to performer training contexts, one can view these contexts as microcosms of social life. Performers 'bodymindly' attend with and to the embodied presences of others and with the ways in which meanings and understandings are constituted through such relational experiences (Csordas 1993:138, 141). The experiences and understandings mentioned above and the embodiment thereof occur in 
the context of what is being learned and are constituted and mediated through emotion (Hannaford 1995:56). At the same time, emotion arises in and through contextually grounded, participatory interactions and learning experiences that many performer-training methodologies offer. As emotion is a key constituent of bodymind, and as embodiment allows individuals to experience themselves as simultaneously in and as their bodyminds (a notion borrowed from Lyon and Barbalet (1994:54) referring to body) in the learning process, emotion becomes embedded in all modes of knowing and learning. This implies that the role of emotion in bodymind engagement can further work towards positioning the body as (a knowing) subject though processes of memory making and learning.

The emotional state of bodymind of the performer-in-training will either support or impede the learning processes of the four metaphorical quadrants. The role of emotion in learning is acknowledged by Herrmann in the lower right quadrant. However Damasio (1999), Le Doux (1996), and Hannaford (1995) argue that an optimal emotional state must be a prerequisite for optimal learning to take place. Carter (1999:164) stresses the engagement of emotion in the making of memory. Hannaford (1995:56) argues that bodymind learns through experiencing life in context and in connection to everything else and that emotions and/or feelings mediate this context. In order to learn, think or create, learners must have an emotional commitment to the learning process and the learning process must in turn stimulate emotions. This is, as indicated above, due to the role of the limbic system encapsulating emotion in relation to cognition. Damasio (1999), Gardner (1999) and LeDoux (1996), basing their argument on neurological evidence, advocate the integration of cognition and affect (emotion) and, as such, support the notion of interrelated thinking and feeling processes.

When applying the above arguments and considering the scholarly survey around Herrmann's metaphorical four-quadrant model, various notions arise.

Emotions cannot just be confined to one quadrant, as emotions determine the basic climate in which the learning process has to occur. Caine et al. (2005:18) posit that the optimal emotional state for learning is what they define as "Relaxed Alertness". This, according to Caine et al. (2005:5), is created in the learner by providing learning opportunities of "low threat and high challenge". Relaxed alertness leads to a feeling of competence, confidence and intrinsic motivation. As such it provides a potent climate for deep structure learning to take place in. 
Learning flourishes when learning occurs through and in bodymind and when emotion is inserts itself as an osmosis ${ }^{9}$-like process flowing between various styles of knowing and learning within the context of bodymind. This thus implies a seamless integration of, and an interdependency of, affective and cognitive learning processes that are simultaneously accessed as a channel within a learning moment.

In the light of the above, bodymind surfaces as a centrifugal force in the learning process. We contend that the Herrmann model does not optimally explain deep structure learning and therefore propose a revised model of whole-brain learning that infuses the existing model with bodymind and emotion to enhance optimal learning. In this revised model the knowing and learning processes associated with the four metaphorical quadrants are operative through and in bodymind. Emotion generated by and in bodymind channels free-flow interaction between the quadrants, thereby facilitating deep-structure learning, meta-learning and meta-cognition. As such, it acts as a learning process and a mode of knowing in itself. It is this model that is organically embedded in many methodologies used in the training of performers.

\section{Figure 2: Revised model}

\section{META-LEARNING}

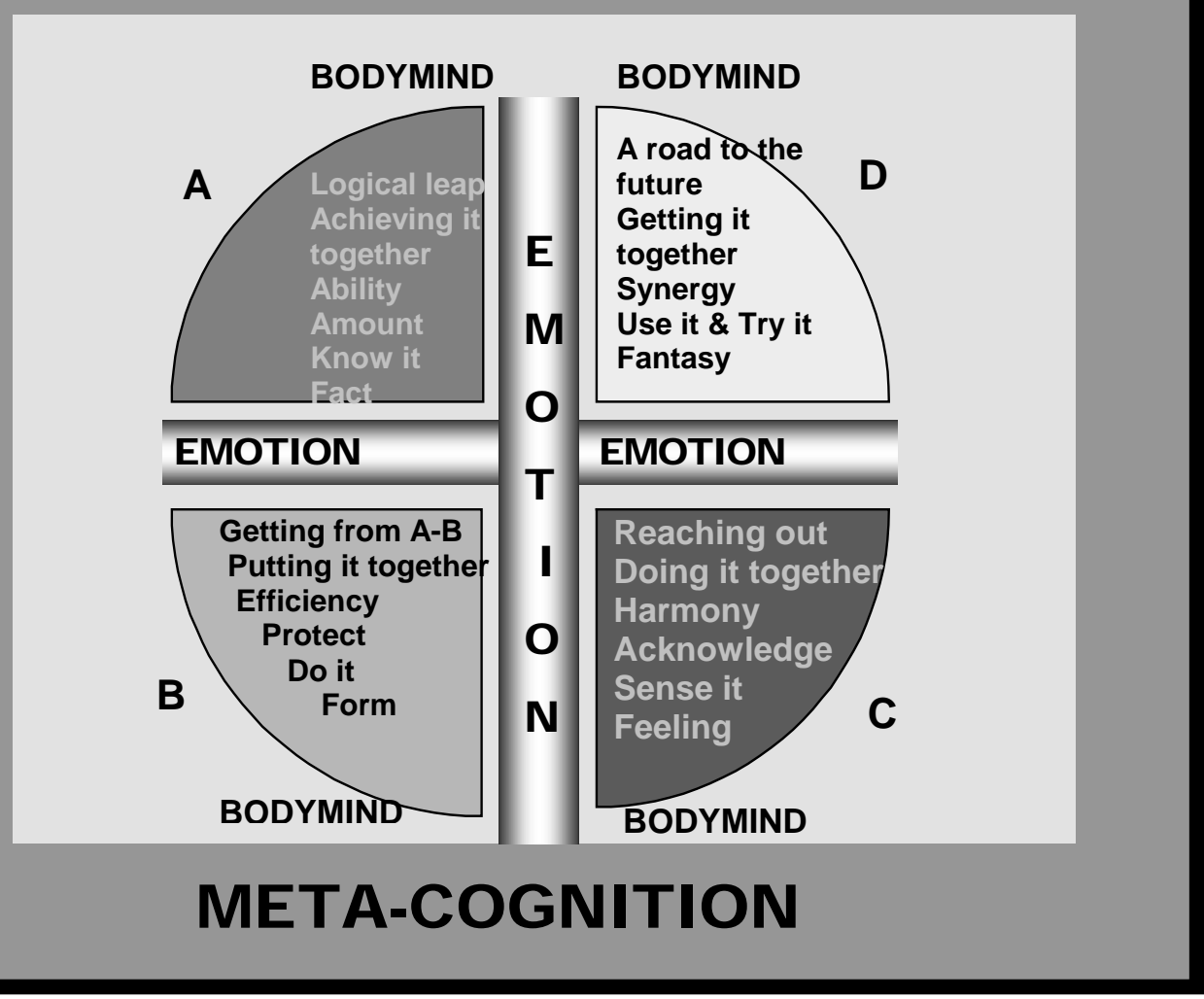


With the four quadrants embedded in bodymind, or bodymind encapsulating the four quadrants -- drawing from and supporting the monist argument - optimal deep-structure learning will take place. Bodymind connectivity is thus far more than a benefit of learning through drama/theatre, but is the driving force and "key ingredient" of learning experiences associated with methodologies used in performer training. The integration of bodymind processes, which includes emotion within learning processes, accommodates diversity in terms of learning styles and learning preferences, and accesses the processes necessary to create a discourse between the metaphorical quadrants.

Methodologies used in performer training thus answer to the demands of OBE, compliments our institutions' advocacy of whole-brain learning as pedagogical foundation for education and training, and, importantly, expands the concept of whole-brain learning. An approach to education that mobilises bodymind towards optimal and deep-structure learning will enable educators to create a climate conducive to optimal learning, explore appropriate methodologies to integrate the metaphorical quadrants and to teach towards optimal learning. It will further assist educators to access the extra-cognitive modes of knowing and learning that are not overtly indicated in the Herrmann model, but without which optimal and deep-structure learning becomes problematic. Embedding Herrmann's four-quadrant model within bodymind, which includes emotion, not only re-shapes the Herrmann model, but potentially refines the landscape of higher education. It further places the training of performers at Drama departments within the locus of Higher Education and Training.

\section{Notes}

1) We express our gratitude to Prof. Allan Munro for his valuable input. We thank the two SATJ peer reviewers for their helpful comments.

2) The critical outcomes are: to identify and solve problems and make decisions using critical and creative thinking; to work effectively with others as members of a team, a group and organisation and a community; to organise and manage themselves and their activities responsibly and effectively; to collect, organise, analyse and critically evaluate information; to communicate effectively using visual, symbolic and/or language skills in various modes; to use science and technology effectively and critically; to demonstrate responsibility towards the environment and health of others; to demonstrate an understanding of the world as a set of related systems by recognising that problem solving contexts do not exist in isolation (Coetzee, Munro \& De Boer, 2004:186-187).

3) Kozik-Rosabal (2001:104-105) explains the intersection between the brain, body, mind and emotion by referring to research on the limbic system and biophysics. She concludes that emotion has a "physical substrate" and that "bodies are minds".

4) Although the authors acknowledge the problematic surrounding the popular reading of Descartes as enforcing a hierarchical (locating the body in subjectivity and the mind in objectivity, as Csordas 
(1994:9) indicates) mind-body dichotomy, addressing this issue falls outside of the scope of this paper. Suffice it to say that alternative readings of Descartes propose that Descartes viewed dualism as a methodological distinction to aid scientific analysis and create a greater separation between science and theology (Csordas, 1994:7; Fraser \& Greco, 2005:6; 48). The authors understand Cartesian dualism as locating the body in subjectivity and the mind in objectivity.

5) See Searle (1992).

6) Time, space, history and culture for example.

7) One can refer here to early Western examples such as The Thinking Body (Todd, 1937) and Man's Supreme Inheritance (Alexander, 1910). From the East the best-known practices and explanations of bodymind can be found in Yoga (Saraswati, 1996). From the discipline of music one can refer to The Mozart Effect (Campbell, 2001) and Bodymind and Voice (Thurman and Welch, 1997). From the field of psychotherapy the work of Rossi (1993) comes to mind. One of the most current writers on this subject is Joseph Chilton Pearce (Mercogliano and Debus, 1999).

8) The 'limbic system' is a term coined by Mclean to refer collectively to specific structures in the midbrain area (Jensen 1998:117). Jensen (1998:9) states that the limbic system facilitates the workings of emotions, attention, sexuality and restfulness.

9) It is difficult to explain the exact functionality of emotion within the whole-brain framework. We posit the idea of osmosis as a way of metaphorising this process. Osmosis might be defined as "movement of a liquid through a membrane from a higher to a lower concentration; process of subtle influence." (Collins Paperback Dictionary and Thesaurus, 2000). As such, emotion enhances free flow between quadrants.

\section{References}

About Learning. 2007. [O]. Available: http://www.aboutlearning.com/. Accessed 20/02/07.

ALEXANDER, F.M. 1910. Man's Supreme Inheritance. UK: Mauritz.

ANDREASSON, N.C. 1997. Linking mind and brain in the study of mental illness: A project for a scientific psychopathology. Science. 275: 1586-1593.

BOGART, A. \& LANDAU, T. 2005. The Viewpoints book: a practical guide to viewpoints and composition. New York: Theatre communications group.

Braindominance. Available: http://braindominance-ppg.blogspot.com. Accessed 14/05/2007

CAINE, R.M, CAINE, G., McCLINTIC, C. \& KLIMEK, K. 2005. 12 Brain/Mind learning principles in action: The fieldbook for making connections, teaching, and the human brain. Thousand Oaks, California: Corwin Press.

CAMPBELL, D. 2001. The Mozart Effect. London: Hodder and Stoughton.

CARTER, R. 1999. Mapping the Mind. Berkeley: University of California Press.

COETZEE, E (ed). 2004. An Introduction to Theory of Education: Current Challenges in Education. Pretoria: Prof. IEM Coetzee.

COETZEE, M-H \& MUNRO, M. 2007. Drama-in-education: echoing outcomes-based education and wholebrain learning. Submitted for peer review.

COETZEE, M-H., MUNRO , M \& DE BOER, A-L. 2004. Deeper sites through various lines: LMS and wholebrain learning in body/voice training for performers in the HET band. In SATJ (18): 134-158.

CSORDAS, T. (ed). 1994. Embodiment and experience: the existential ground of culture and self. Cambridge: Cambridge University Press.

CSORDAS, T. 1993. Somatic Modes of Attention. Cultural Anthropology 8(2): p.135-156. 2007. [O]. Available: http://www.jstor.org/browse/08867356. Accessed 14/05/07.

DAMASIO, A. 1999. The feeling of what happens: Body and emotion in making of consciousness. New York: Harcourt Brace.

DAMASIO, A. 1994. Descartes' Error: Emotion, Reason and the Human Brain. New York: Avon Books.

DE BOER, A-L, STEYN, T \& DU TOIT, P. H. 2001. A whole brain approach to teaching and learning in higher education. In SAJHE (15):3.

DIAMOND, C. T.P. \& MULLEN, C. I teach, therefore I am. 2002. In Mirochnik, E. and Scherman, D.C. (eds). Passion and pedagogy: relation, creation, and transformation in teaching. New York: P. Lang. Differentiated Learning and Differentiated Instruction lessons feature US-American History lesson projects to use in elementary and middle schools for differentiated learning instruction strategy. 2007. [O]. Available: http://www.funlessonplans.com/history_map.htm. Accessed 20/02/07.

DU TOIT, P. 2001. Learning style differentiated learning. Education induction programme, University of Pretoria, 2002.

FRASER, M \& GRECO, M (eds). 2005. The Body: A Reader. London: Routledge Student Readers.

GARDNER, H. 1999. Intelligence Reframed. Multiple intelligences for the $21^{\text {st }}$ century. New York: Basic Books.

HANNAFORD, C. 1995. Smart Moves - why learning is not all in your head. Atlanta: Great Ocean Publishers. 
HASKELL, J \& LINDS, W. Unfolding bodymind: exploring possibility through education. Vermont: Foundation for Educational Renewal. In Hocking, B. Haskell, J and Linds, W. (eds). Unfolding bodymind: exploring possibility through education. Vermont: Foundation for Educational Renewal.

HASKELL, J. 2001. Experiencing unknown landscapes: Unfolding a path of embodied respect. In Hocking, B. Haskell, J and Linds, W. (eds). Unfolding bodymind: exploring possibility through education. Vermont: Foundation for Educational Renewal. p. 282-2297.

HERRMANN, N. 1995. The Creative Brain. North Carolina: The Ned Herrmann Group.

HERRMANN, N. 2000. The theory behind the HBDI and the whole brain technology. [O]. Available: www.herrmann.com.au/pdfs/articles/TheTheoryBehindHBDI.pdf. Accessed 12/07/2007.

HERRMANN, N. 2001. Measurement of Brain Dominance. [O]. Available: www.herrmann.com.au/pdfs/articles/MeasurementofBrainDominance.pdf Accessed 12/07/2007.

HOCKING, B. HASKELL, J \& LINDS, W. 2001. Re-imagining worlds through education: An overview of the book and its influences. In Hocking, B., Haskell, J and Linds, W. (eds). Unfolding bodymind: exploring possibility through education. Vermont: Foundation for Educational Renewal.

HOCKING, B. HASKELL, J \& LINDS, W. 2001. Unfolding bodymind: exploring possibility through education. Vermont: Foundation for Educational Renewal.

HODGE, A. 2000. Twentieth-century actor training. London: Routledge.

JENSEN, E. 1998. Teaching with the brain in mind. Alexandria: Virginia, USA: Association for Supervision and Curriculum Development.

KOZIK-ROSABAL, G. 2001. How do they learn to be whole? A strategy for helping preservice teachers develop dispositions. In Hocking, B. Haskell, J and Linds, W. (eds) Unfolding bodymind: exploring possibility through education. Vermont: Foundation for Educational Renewal. p. 282-2297.

LE DOUX, J.E. 1996. The emotional Brain. New York: Simon and Schuster.

LYON, M. \& BARBALET, J. 1994. Society's body: emotion and the "somatization" of social theory. In Csordas, T. (ed). 1994. Embodiment and experience: the existential groung of culture and self. Cambridge: Cambridge University Press.

MADDEN, P. \& GANTZ, J. 1989. Laban Movement Studies: A Program in Body-Mind Education. In The Educational Forum, 54(1):117-122.

MERCOGLIANO, C \& DEBUS, K. 1999. An Interview with Joseph Chilton Pearce. In Journal of Family Life Magazine. 5(1). http://www.appliedmeditation.org/The_Heart/articles_joseph_Chilton_pearce.shtml. Accessed 19/06/2007.

MERLEU-PONTY, M. The Experience of the Body and Classical Psychology. In Fraser, M and Greco, M (eds). 2005. The Body: A Reader. London: Routledge Student Readers.

MIROCHNIK, E. \& SCHERMAN, D.C. (eds). 2002. Passion and pedagogy: relation, creation, and transformation in teaching. New York: P. Lang.

MUNRO, M. \& COETZEE, M-H. 2005. The Lessac approach as a pedagogical answer to outcomes-based education and training, and whole-brain learning. In VASTA Voice and Speech Review. 4:186-192.

NORMAN, J. 1999. Brain right drama. In Drama Magazine. Summer:8-13.

PERT, C.B. 1986. The Wisdom of Receptors: Neuropeptides, the emotions, and bodymind. In Avances 3(3): 8-16.

Review of clinical and functional neuroscience. Chapter 9. $2007 . \quad$ [O]. Available: http://www.dartmouth.edu/ swenson/NeuroSci/chapter_9.html. Accessed 13/03/07.

RICHARDS, T. 1995. At work with Grotowski on Physical Actions. London: Routledge.

ROSSI, E. L. 1993. The Psychobiology of Mind-body Healing: New Concepts of Therapeutic Hypnosis. New York USA: W.W. Norton and Company, Inc.

SARASWATI, S. 1996. Asana Pranayama Mudra Bandha. India: Yoga Publications.

SEARLE, J, R. 1992. The Rediscovery of the Mind. Cambridge, MA: MIT press.

TABISH, R. 1995. Kinesthetic Engagement Technique: Theories and Practices for Training the Actor. University of Pittsburgh: Unpublished PhD dissertation. UMI Dissertation Services.

THURMAN, L \& WELCH, G (eds). 1997. Bodymind and Voice: Foundation of Voice Education. Minneapolis USA: The VoiceCare Network, National Center of Voice and Speech, The Voice Center of Fairview Arts Medicine Center.

TODD, M, E. 1937. The Thinking Body: A Study of the Balancing Forces of Dynamic Man. Pennington, NJ: Princeton Book Company.

WATSON, I. 2001. Performer Training: Development Across Cultures. Australia Amsterdam: Harwood Academic Publishers.

WOLFORD, L. 2000. Grotowski's vision of the actor. In Hodge, A. 2000. Twentieth-century actor training. London: Routledge.

ZARRILLI, P.B. (ed). 2002. Acting (re)considered. A theoretical and practical guide. (2 ${ }^{\text {nd }}$ Edition). London: Routledge. 